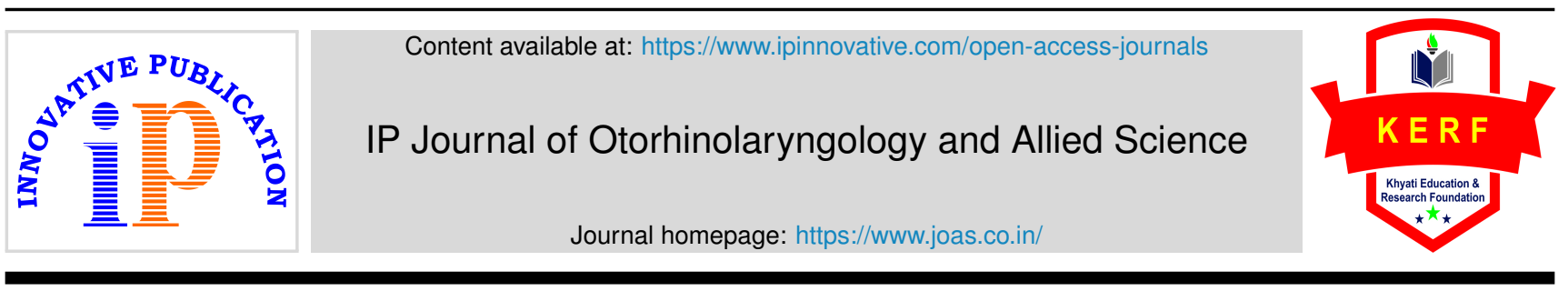

Original Research Article

\title{
A study on the role of Functional Endoscopic Sinus Surgery (FESS) in allergic rhinitis patients with chronic sinusitis and nasal polyposis
}

\author{
Sharmila Dhulipalla ${ }^{1}$,*, Pitta Narayana Rao $^{1}$, Gampala Sravya Vinuthna ${ }^{1}$ \\ ${ }^{1}$ Dept. of ENT, Katuri Medical College and Hospital, Guntur, Andhra Pradesh, India
}

\section{A R T I C L E I N F O}

\section{Article history:}

Received 06-03-2021

Accepted 31-03-2021

Available online 20-04-2021

\section{Keywords:}

Chronic sinusitis

Allergic Rhinitis

FESS

SNOT score

\begin{abstract}
A B S T R A C T
Background: The role of sinus surgery in the management of allergic rhinitis with chronic rhinosinusitis patients has been a debatable matter for many years. We are presenting a well-designed prospective, controlled study in 80 patients with allergic rhinitis and chronic rhinosinusitis (CRS) with or without nasal polyposis who were submitted to functional endoscopic sinus surgery (FESS).

Materials and Methods: In this study we have selected 80 patients of age group 15 to $60 \mathrm{yrs}$ diagnosed to have allergic rhinitis with chronic sinusitis \& nasal polyposis attending the department of otorhinolaryngology. Patients undergoing FESS were included in the study group (40 cases) and those who refused for surgery (FESS) and continuing with medical treatment were included in the control group (40 cases). All patients both study and control group underwent pretreatment and post-treatment evaluation for SNOT 22 score. Statistical differences in proportions were compared by Chi-square test and differences in means were compared by the unpaired t-test.

Result: Our results indicated that all patients showed some level of improvement post-operatively, with an average improvement in the total symptom score (reduction in SNOT-22 composite score) of 54\% of baseline, pre-operative value Significant improvement was observed in SNOT 22 scores in patients treated with FESS $(\mathrm{p}<0.001)$.

Conclusion: FESS is effective in controlling symptoms of allergic rhinitis with chronic sinusitis and nasal polyposis. Our clinical study supports the hypothesis that FESS has a positive influence in patients with allergic rhinitis and chronic sinusitis and nasal polyposis.
\end{abstract}

(C) This is an open access article distributed under the terms of the Creative Commons Attribution License (https://creativecommons.org/licenses/by/4.0/) which permits unrestricted use, distribution, and reproduction in any medium, provided the original author and source are credited.

\section{Introduction}

Allergic rhinitis is the most prevalent and common disorder, with more than 600 million patients afflicted worldwide and the incidence is steadily increasing. ${ }^{1-3}$ The central complaint of nasal obstruction accounts for one of the most common reasons for outpatient otolaryngologic visits. Indeed, many interventions exist for the treatment of allergic rhinitis, which has been referred to as the 'total rhinologic disease. ${ }^{4,5}$ The most common surgical interventions are aimed at alleviating nasal obstruction to better reduce static obstruction while improving compliance of the nasal passages. Poorly controlled allergic rhinitis may also

\footnotetext{
* Corresponding author.

E-mail address: dhulipallasharmila@yahoo.com (S. Dhulipalla).
}

contribute to the development of other related disease processes including acute and chronic sinusitis, recurrence of nasal polyps, otitis media /otitis media with effusion, hearing impairment, abnormal craniofacial development, sleep apnea and related complications, aggravation of underlying asthma, and increased propensity to develop asthma.

Functional endoscopic sinus surgery (FESS) has been an increasingly popular treatment for chronic sinus disease and nasal polyposis. In chronic sinus disease, secondary to allergic rhinitis, inflammatory process affect sinus mucosa leading to edema of the mucosa in the region of osteomeatal complex. Osteomeatal complex is an area where frontal, maxillary and anterior ethmoids drain. This small area is key to proper physiological functions of the sinuses. The 
obstruction of mucociliary clearance in this area, tissue hypoxia, stasis of secretions, bacterial overgrowth and cycle of worsening inflammation and obstruction then leads to irreversible changes in sinus mucosa which will then require surgical debridement. This goal is achieved by the endoscopic removal of disease from key areas of the anterior ethmoid and middle meatus. It reestablishes the ventilation, mucociliary clearance and the return of normal functioning of the sinuses. In this paper we aim to estimate the effect of endoscopic sinus surgery on health-related quality of life, as recorded in pre and postsurgical SNOT-22 questionnaires.

\section{Materials and Methods}

Our study comprises of 80 patients in the age group of 15 to 60 years diagnosed to have allergic rhinitis and chronic sinusitis with polyposis, who are on medical treatment (in the form of broad spectrum antibiotics, antihistamines, leukotriene inhibitors, topical steroid sprays) for at least 6 weeks duration. These patients were evaluated in reference to sinonasal symptoms, endoscopic appearance of nasal cavity and osteomeatal complex (OMC), radiographic study (CT scan) of nose and PNS and allergic symptoms. Forty patients undergoing FESS for CRS with polyposis were included in the study group. Forty patients who refused surgery (FESS) for CRS and polyposis and having allergic rhinitis and are continuing medical treatment were included in the control group.

Revision and recurrent cases of sinusitis after surgery were excluded from the study. Patients younger than 15 years, those with primary immunodeficiency, ciliary dyskinesia, cystic fibrosis and malignant tumors were excluded from the study. Patients with psychiatric illness were also excluded from the study as their ability to give reliable information regarding their nasal disease could be disputed. Diagnoses of both the groups were based on clinical and radiological methods. All patients both study and control group underwent pretreatment and posttreatment evaluation for SNOT 22 score. Each subject completed the SNOT-22 during a clinic visit by answering all questions based on a $0-5$ scale, where 0 defines no problems with the given symptom and 5 defines maximal problems (Table 1). This is a validated patient-reported measure of outcome established to delineate the presence and severity of sinonasal disorders. ${ }^{6}$

FESS was done in all the study group patients following the technique put forth by Messerklinger and Stammberger. ${ }^{7}$ Uncinectomy and middle meatal antrostomy was carried out in almost all patients. The extent of procedure was tailored to the extent of sinus disease as documented by CT scan and nasal endoscopic findings. Postoperatively merocele packs were used for anterior nasal packing, which were removed $24 \mathrm{~h}$ later. These patients were discharged on the 2nd or 3rd postoperative day. Postoperatively all the patients were instructed to use alkaline nasal douching till the nasal crusting reduced (2-3 weeks), and were reviewed at 10th day, 1 month, 3 month and 6th month. At each visit patients symptoms were assessed and endoscopic examination and toileting were done. At 1 month, 3month and 6 months visit Standard protocol for all patients presenting for evaluation also included completion of the SNOT-22 prior to and following surgical intervention. All patients underwent pretreatment and post-treatment evaluation for SNOT 22 score. Statistical differences in proportions were compared by Chi-square test and differences in means were compared by the unpaired $t-$ test.

\section{Results}

There were 56(70\%) males and $24(30 \%)$ females in our study (Table 2 ). The age ranged from 15 to 60 years with $50 \%$ of patients falling into young age group i.e. 15 to 30 years. Maxillary sinus was involved in all cases. Twenty two out of 80 involved all the sinuses including maxillary, anterior ethmoids, posterior ethmoids, frontal and sphenoids. Unilateral involvement was seen in 8 cases. Almost all patients presented with a history of nasal obstruction (75/80). Nasal discharge and post nasal drip were also common.

Preoperative diagnostic nasal endoscopy showed Deviated nasal septum in $75 \%$ of patients, inferior turbinate hypertrophy in $70 \%$ of patients, watery discharge on floor of nasal cavity in $68 \%$ of patients, mucopurulent discharge in middle meatus in $56 \%$ of patients, polpys in middle meatus seen in $50 \%$ of patients (Table 3 ).

In our study we used the patient outcome measure Sino Nasal Outcome Test-22 (SNOT-22) which is validated to assess the preoperative and postoperative quality of life in patients undergoing Functional endoscopic sinus surgery. All the patients were assessed by SNOT score pretreatment and at the end of 1, 3 and 6 months post treatment to know the efficiency of the FESS treatment on allergic rhinitis control. Our results indicated that all patients showed some level of improvement post-operatively, with an average improvement in the total symptom score (reduction in SNOT-22 composite score) of $54 \%$ of baseline, preoperative values. (Table 4) Significant improvement was observed in SNOT 22 scores (Table 5) in patients treated with FESS $(\mathrm{p}<0.001)$.

\section{Discussion}

Allergic Rhinitis is defined as a disorder of the nasal symptoms which is induced after allergen exposure and mediated by an IgE antibody inflammation of the nasal mucosa. The clinical features include rhinorrhoea (anterior or posterior), nasal congestion, nasal itching, and sneezing. ${ }^{8}$ The companionship between allergic rhinitis and sinusitis is confirmed in many studies, but the effect of sinusitis 
Table 1: Sino Nasal Outcome Test 22 - Questionnaire

\begin{tabular}{|c|c|c|c|c|c|c|}
\hline $\begin{array}{l}\text { A: Considering the severity } \\
\text { of problem when you } \\
\text { experience it and how } \\
\text { frequently it happens, please } \\
\text { rate each item below on how } \\
\text { 'bad' it is by circling the } \\
\text { number that corresponds } \\
\text { with how you feel using this } \\
\text { scale } \rightarrow\end{array}$ & $\begin{array}{l}\text { No } \\
\text { problem }\end{array}$ & $\begin{array}{l}\text { Very mild } \\
\text { problem }\end{array}$ & $\begin{array}{l}\text { Mild or } \\
\text { slight } \\
\text { problem }\end{array}$ & $\begin{array}{l}\text { Moderate } \\
\text { problem }\end{array}$ & $\begin{array}{l}\text { Severe } \\
\text { problem }\end{array}$ & $\begin{array}{l}\text { Problem as } \\
\text { bad as it can } \\
\text { be }\end{array}$ \\
\hline 1. Need to blow nose & 0 & 1 & 2 & 3 & 4 & 5 \\
\hline 2. Sneezing & 0 & 1 & 2 & 3 & 4 & 5 \\
\hline 3. Runny nose & 0 & 1 & 2 & 3 & 4 & 5 \\
\hline 4. Cough & 0 & 1 & 2 & 3 & 4 & 5 \\
\hline $\begin{array}{l}\text { 5. Post nasal discharge } \\
\text { (dripping at the back of your } \\
\text { nose) }\end{array}$ & 0 & 1 & 2 & 3 & 4 & 5 \\
\hline 6. Thick nasal discharge & 0 & 1 & 2 & 3 & 4 & 5 \\
\hline 7. Ear fullness & 0 & 1 & 2 & 3 & 4 & 5 \\
\hline 8. Dizziness & 0 & 1 & 2 & 3 & 4 & 5 \\
\hline 9. Ear pain & 0 & 1 & 2 & 3 & 4 & 5 \\
\hline 10. Facial pain/pressure & 0 & 1 & 2 & 3 & 4 & 5 \\
\hline 11. Difficulty falling asleep & 0 & 1 & 2 & 3 & 4 & 5 \\
\hline 12. Waking up at night & 0 & 1 & 2 & 3 & 4 & 5 \\
\hline 13. Lack of a good night's sleep & 0 & 1 & 2 & 3 & 4 & 5 \\
\hline 14. Waking up tired & 0 & 1 & 2 & 3 & 4 & 5 \\
\hline 15. Fatigue & 0 & 1 & 2 & 3 & 4 & 5 \\
\hline 16. Reduced productivity & 0 & 1 & 2 & 3 & 4 & 5 \\
\hline 17. Reduced concentration & 0 & 1 & 2 & 3 & 4 & 5 \\
\hline 18. Frustrated/restless/ irritable & 0 & 1 & 2 & 3 & 4 & 5 \\
\hline 19. Sad & 0 & 1 & 2 & 3 & 4 & 5 \\
\hline 20. Embarrassed & 0 & 1 & 2 & 3 & 4 & 5 \\
\hline 21. Sense of taste/smell & 0 & 1 & 2 & 3 & 4 & 5 \\
\hline $\begin{array}{l}\text { 22. Blockage/congestion of } \\
\text { nose }\end{array}$ & 0 & 1 & 2 & 3 & 4 & 5 \\
\hline
\end{tabular}

Table 2: Sex distribution of patient studied

\begin{tabular}{llll}
\hline S.No. & Sex & Number of patients & Percentage \\
1 & Males & 56 & 70 \\
2 & Females & 24 & 30 \\
\hline
\end{tabular}

Table 3: Distribution ofpatients according to their Diagnostic nasal endoscopy findings (DNE).

\begin{tabular}{llccc}
\hline S.No & DNE Finding & No of Cases & Total Cases & Percentage \\
1 & Deviated nasal septum & 60 & 80 & $75 \%$ \\
2 & Inferior turbinate hypertrophy & 56 & 80 & $70 \%$ \\
3 & Watery discharge on floor & 54 & 80 & $68 \%$ \\
4 & Mucopurulent discharge in middle meatus & 45 & 80 & $56 \%$ \\
5 & Polyps in middle meatus & 40 & 80 & $50 \%$ \\
\hline
\end{tabular}

Table 4: Post-operative SNOT-22 improvement as a function of Pre-operative SNOT-22 in study group.

$\begin{array}{ccc}\text { Pre-Operative Score } & \text { Absolute Improvement } \text { units } & \text { Percent Improvement } \% \\ 16 & 5.4 & 36.0 \\ 28 & 16.2 & 54.7 \\ 44 & 25.3 & 57.1 \\ 60 & 32 & 54.1\end{array}$


Table 5: SNOT 22 score

\begin{tabular}{lccc}
\hline SNOT 22 score & Study group & Control group & P - value \\
Pretreatment & $12.40 \pm 2.46$ & $18.04 \pm 0.79$ & $\mathrm{p}<0.001$ \\
Post-treatment 1 month & $22.48 \pm 1.96$ & $21.12 \pm 0.78$ & $\mathrm{p}<0.001$ \\
Post-treatment 3 months & $23.84 \pm 1.47$ & $19.40 \pm 1.29$ & $\mathrm{p}<0.001$ \\
Post-treatment 6 months & $23.84 \pm 1.48$ & $18.92 \pm 1.21$ & $\mathrm{p}<0.001$ \\
Mean post-treatment & $23.38 \pm 1.35$ & $19.81 \pm 1.33$ & $\mathrm{p}<0.001$ \\
\hline
\end{tabular}

treatment on symptoms of allergic rhinitis, especially the outcome after undergoing functional endoscopic sinus surgery, is still controversial. In most of the previous studies, selected subjective and objective variables were limited and could not entirely evaluate the outcome of sinus surgery in these patients. Also the studies were mostly not controlled. Therefore, the effects of functional endoscopic sinus surgery on subjective improvement of allergic rhinitis patients with chronic sinusitis were evaluated in our study. Because of improved understanding of pathogenesis of sinusitis, FESS has emerged as the surgical procedure of choice for chronic sinusitis. Functional endoscopic sinus surgery has revolutionized the treatment of sinonasal disease as it reestablishes ventilation and mucociliary clearance by limited resection of inflammatory or anatomical defect at the osteomeatal complex area. ${ }^{9}$ The concept of FESS is the removal of tissue obstructing the osteo metal complex (OMC) and the facilitation of drainage and ventilation while conserving the normal non-obstructing anatomy and mucous membrane, which is essential for mucosal regeneration. The rigid fiberoptic nasal telescope provides superb intraoperative visualization of the OMC, allowing the surgery to be focused precisely on the key areas to achieve the main goal: Adequate and permanent postoperative patency of sinuses. ${ }^{10}$

Endoscopic sinus surgery has several advantages over more conventional techniques, like Caldwell-Luc etc. First, the patient is spared the additional trauma of external skin or mucous membrane incisions and the accompanying removal of intervening bone. Second, as with the use of the microscope in ear surgery, endoscopes permit unparalleled visualization of the sinuses and the anatomy of the lateral nasal wall. Third, improved visualization allows more accurate diagnosis of malformations or obstructing masses, such as polyps, in the osteomeatal region. Fourth, there is precise removal of sinus disease with preservation of mucus membrane and restoration of normal mucociliary transport. ${ }^{11}$

There are various theories about the association between Allergic Rhinitis and Chronic Rhinosinusitis. One theory hypothesised is that allergy causes edema of the mucosa, which obstructs the osteomeatal complex and affects mucocilliary transport, and possibly induces rhinosinusitis. $^{12}$ Another theory proposed that there is significant inflammation (eosinophils) in the maxillary sinus of allergic patients during the season than out of season. ${ }^{12,13}$
Endoscopic sinus surgery is primarily of indirect benefit in allergic rhinitis patients who present with concomitant rhinosinusitis, sinonasal polyposis, or allergic fungal sinusitis. The goal of endoscopic surgery is to maximize the nasal patency and to alleviate the effects of edematous ostia. Obstruction in the osteometal unit hampers mucociliary drainage leading to chronic sinusitis. The microanatomy of osteomeatal complex and other hidden areas can be easily defined by CT scan paranasal sinuses which acts as a roadmap for surgery. Functional endoscopic sinus surgery brings about restoration of natural mucociliary clearance mechanism, drainage and aeration of sinuses, and resolution of apparently irreversible polypoidal mucosa without interfering with the normal mucosa of the sinuses. Surgical reduction of polyposis and maximal opening of air cells and ostia will assist with medical and topical therapies, while reducing recurrent bouts of sinusitis. ${ }^{14}$ This is of utmost importance in allergic rhinitis patients to enhance the quality of life. Endoscopic interventions may also be combined with turbinoplasty to provide benefit in more difficult or advanced cases of allergic rhinitis, in which turbinate reduction alone may be inadequate.

Importantly, FESS provides the opportunity to open windows into the sinuses that did not previously exist, thereby improving the application of post-operative medical treatments, including steroids. ${ }^{15,16}$ The addition of these windows might explain the differences in post-operative improvement when compared to those patients with no prior surgeries. With optimal surgical intervention (and post-operative medical management), FESS is an extremely effective treatment of Chronic Rhinosinusitis. Patient-based outcome measures, such as the SNOT-22, are helpful tools for quantifying changes in clinical symptoms and can be used to predict extent of post-operative improvement. As it is validated from Hopkins and colleagues, Sino Nasal Outcome Test - 22 (SNOT-22) has become the reference questionnaire to estimate the health status and health-related quality of life in CRS. ${ }^{17}$

\section{Conclusion}

Allergic rhinitis is a very common condition. When allergic rhinitis is poorly controlled, it contributes to the development of chronic sinusitis and nasal polyposis. The key surgical objective of treating allergic rhinitis with chronic sinusitis and nasal polyposis is to augment 
the nasal airway by primarily reducing turbinate tissue, correcting septum and endoscopic sinus surgery involving uncinectomy, anterior ethmoidectomy, MMA and posterior ethmoidectomy for polyps, thereby alleviating the most common complaint of nasal obstruction. FESS is effective in controlling symptoms of allergic rhinitis with chronic sinusitis and nasal polyposis. Our clinical study supports the hypothesis that FESS has a positive influence in patients with allergic rhinitis and chronic sinonasal polyposis.

\section{Conflicts of Interest}

All contributing authors declare no conflicts of interest.

\section{Source of Funding}

None.

\section{References}

1. Beasley R, Keil U, and EVM. The international study of asthma and allergies in childhood (ISSAC) study of asthma and allergies in childhood (ISSAC) steering committee. Worldwide variation in prevalence of asthma, allergic rhino conjunctivitis, and atopic eczema: ISSAC. Lancet. 1998;351:1225-32.

2. Wright AL, Holberg CJ, Martinez FD. Epidemiology of physiciandiagnosed allergic rhinitis in childhood. Pediatr. 1994;94:895-901.

3. Nathan RA, Meltzer E, Derebery J, Campbell UB, Stang PE, Corrao MA, et al. The prevalence of nasal symptoms attributed to allergies in the United States: Findings from the burden of rhinitis in an America survey. Allergy Asthma Proc . 2008;29(6):600-8. do1:10.2500/aap.2008.29.3179.

4. Krause HF. Allergy and chronic rhino sinusitis. Otolaryngol Head Neck Surg. 2003;128:14-6.

5. Trevino R, Gordon B. Allergic rhino sinusitis. ENT J. 1993;72:11629.

6. Hopkins C, Gillett S, Slack R, Lund VJ, Browne JP. Endoscopic sinus surgery-concepts in treatment of recurring rhinosinusitis. Part-II surgical technique. Otolaryngol Head Neck Surg. 1986;34(2):147-56.

7. Stammberger H. Endoscopic Endonasal Surgery-Concepts in Treatment of Recurring Rhinosinusitis. Part II. Surgical Technique. Otolaryngol-Head Neck Surg. 1986;94(2):147-56. doi:-177/010459988609400203.

8. Bousquet J, Khaltaev N, Cruz AA, Denburg J, Fokkens WJ, Togias A, et al. Allergic Rhinitis and its Impact on Asthma (ARIA) 2008 update (in collaboration with the World Health Organization, GA(2)LEN and AllerGen). Allergy. 2008;63(86):8-160. do1:10.1111/1.1398Q995.200701620x:8-160.

9. Smith LF, Brindley PC. Indications, Evaluation, Complications, and Results of Functional Endoscopic Sinus Surgery in 200 Patients. Otolaryngol - Head Neck Surg. 1993;108(6):688-96.

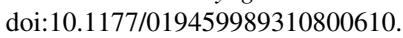

10. Al-Mujaini A, Wali U, Alkhabori M. Functional endoscopic sinus surgery: Indications and complications in the ophthalmic field. Oman Med J. 2009;24:70-80.

11. Schaefer SD, Manning S, Close L. Endoscopic paranasal sinus surgery. Indications and considerations. Laryngoscope. 1989;99:1-5.

12. Fokkens WJ, Lund VJ, Mullol J, Bachert C, Alobid I, Baroody F, et al. European position paper on rhinosinusitis and nasal polyps 2012 . A summary for otorhinolaryngologists. Rhinol J. 2012;50(1):1-12. dol:104प3/rhinosणe2

13. Baroody FM, Mucha SM, deTineo M, Naclerio RM. Evidence of Maxillary Sinus Inflammation in Seasonal Allergic Rhinitis. Otolaryngol-Head Neck Surg. 2012;146(6):880-6.

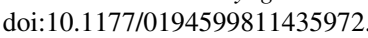

14. Okushi T, Mori E, Nakayama T. Impact of residual ethmoid cells on postoperative course after endoscopic sinus surgery for chronic rhinosinu- sitis. Auris Nasus Larynx. 2011;39(5):484-9.

15. Harvey RJ, Goddard JC, Wise SK, Schlosser RJ. Effects of endoscopic sinus surgery and delivery device on cadaver sinus irrigation. Otolaryngo-Head Neck Surg. 2008;139:137-42. do1:10.1016/].otohns.2008.04.020.

16. Grobler A, Weitzel EK, Buele A, Jardeleza C, Cheong YC, Field J, et al. Pre- and Postoperative Sinus Penetration of Nasal Irrigation. Laryngoscope. 2008;118(11):2078-81. doi:10.1097/mig.0b013e31818208c1.

17. DeConde AS, Smith TL. Outcomes After Frontal Sinus Surgery. Otolaryngol Clin North Am. 2016;49(4):1019-33. do1:10.1016/].0tc.2016.03.024

\section{Author biography}

Sharmila Dhulipalla, Associate Professor

Pitta Narayana Rao, Professor and HOD

Gampala Sravya Vinuthna, House Surgeon

Cite this article: Dhulipalla S, Rao PN, Vinuthna GS. A study on the role of Functional Endoscopic Sinus Surgery (FESS) in allergic rhinitis patients with chronic sinusitis and nasal polyposis. IP $J$ Otorhinolaryngol Allied Sci 2021;4(1):28-32. 